\title{
Mechanical properties of $\alpha$-A12O3/PP nano composite
}

\begin{abstract}
This study has focused on the effect of nano particle $\alpha$-alumina on the mechanical properties of polypropylene composite was studied. The nano composites containing 1-5 wt.\% of $\alpha-$ alumina nano particles were prepared by using a Haake internal mixer. Mixing was performed at $170^{\circ} \mathrm{C}$ and $30 \mathrm{rpm}$ was set for the rotor speed. Some properties such as tensile strength, flexural strength, young modulus and the elongation to break were tested and were found to decrease with the addition of 2-3 wt.\% $\alpha$-nano alumina into the polypropylene matrix. However, with further addition of up to 3 to $5 \mathrm{wt} . \%$ of $\alpha$-nano alumina, these parameters increased. In contrast, flexural modulus increased with an increase in the amount of $\alpha$-nano alumina loading. When the weight percent was increased from 2 to $3 \mathrm{wt} . \%$, the flexural strength was slightly decreased.
\end{abstract}

Keyword: $\alpha$-nano alumina; Polypropylene; Tensile strength; Flexural strength 